\title{
Exertional pain in the thigh: test yourself question and answer
}

\author{
N. Winn ${ }^{1} \cdot$ F. Amary ${ }^{2} \cdot$ K. Shepherd ${ }^{1}$ \\ Published online: 29 October 2020 \\ (C) ISS 2020
}

\section{Test yourself answer: exertional pain in the thigh}

\section{Diagnosis: Mazabraud syndrome with femoral insufficiency fracture}

The radiograph shows characteristic bony changes of fibrous dysplasia of the femur, with a ground-glass texture and "shepherd's crook" deformity. The patient's presentation can be attributed to the insufficiency fracture at the apex of the curve (Fig. 1). The altered structure of the bone increases its risk of fracture if it is subjected to increased functional load [1]. The shepherd's crook deformity results from multiple microfractures within abnormal bone. MRI and CT show typical changes of fibrous dysplasia in the left proximal femur, with geographical altered signal from the marrow and cortical bone and the absence of aggressive features, namely, marrow oedema and periosteal reaction. The Tc-99m HDP bone scan demonstrates increased uptake in the left femur but also in the left tibia, indicating a polyostotic nature to the fibrous dysplasia.

The cross-sectional imaging reveals an intramuscular lesion, which was clinically asymptomatic but palpable. This lesion shows low signal on $\mathrm{T} 1$, high signal on the fatsuppressed sequences (myxoid elements) and modest, incomplete post-contrast enhancement (solid stroma). Whilst these imaging characteristics are not specific for a myxoma, the presence of bone changes of fibrous dysplasia suggests that

The case presentation can be found at doi: https://doi.org/10.1007/ s00256-020-03570-1

N. Winn

naomi.winn@nhs.net

1 The Robert Jones and Agnes Hunt Orthopaedic Hospital NHS Foundation Trust, Oswestry SY10 7AG, UK

2 Royal National Orthopaedic Hospital NHS Foundation Trust, Stanmore, Middlesex HA7 4LP, UK this is the most likely aetiology, in the context of Mazabraud syndrome.

The femoral insufficiency fracture failed to heal with conservative management, necessitating internal fixation with realignment osteotomy, bone biopsy at the fracture and excision of the soft tissue lesion. Histology of the soft tissue lesion showed a paucicellular myxoid tumour with no cytological atypia. Samples of the bone showed a fibro-osseous lesion composed of irregular trabeculae of woven bone in a fibrous stroma, compatible with fibrous dysplasia with pagetoid changes. The sample was small and taken from around the fracture, accounting for the absence of a classical appearance of fibrous dysplasia. A R201H substitution was found in the GNAS1 gene, confirming the diagnosis of fibrous dysplasia.

A mutation in the GNAS1 gene is the genetic hallmark of both the fibrous dysplasia and intramuscular myxomas [2, 3]. This is considered to be post-zygotic, explaining the occurrence of multiple sites, also found in McCune-Albright syndrome (fibrous dysplasia, endocrine tumours and café-au-lait skin pigmentation) [4].

Henschen reported the features of the syndrome initially in 1926 [5], and it was formally recognized as Mazabraud syndrome in 1967 [6]. The defining characteristics are the combination of fibrous dysplasia (polyostotic $>$ monostotic) and myxomas [7].

Sarcomatous transformation is a rare complication and has been described in the bone lesions, with examples of osteosarcoma [8] and high-grade spindle cell sarcoma of the femur [3].

The myxomas are often multiple, more common in the lower limbs and are frequently located close to the bone [9]. Usually they are intramuscular; however, they may also arise from tendons. There are no cases of malignant transformation in the myxomas, but they may present as an enlarging mass.

In summary, Mazabraud syndrome is often clinically silent until patients present with a complication of the bone or soft tissue lesions. It should be considered in patients presenting with multiple soft tissue masses in conjunction with bone lesions. 
Fig. 1 Lateral (a) and AP (b) radiographs, (c) coronal STIR MR image and (d) coronal CT bone reconstruction image of the left femur. The arrows show the insufficiency fracture at the apex of the curve, seen as a subtle break in the cortex and medullary bone (best shown on the radiographs and CT). On MRI, the fracture is seen as a low signal line within the areas of altered signal in the marrow and cortical bone, representative of fibrous dysplasia

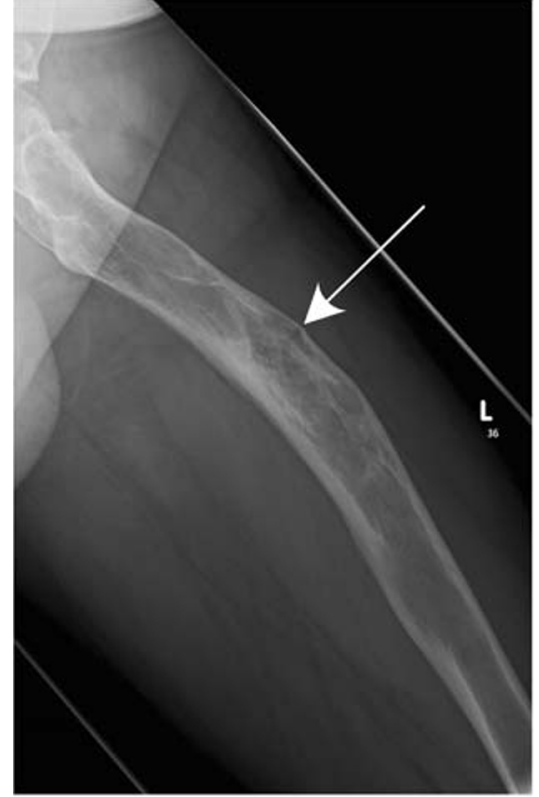

a

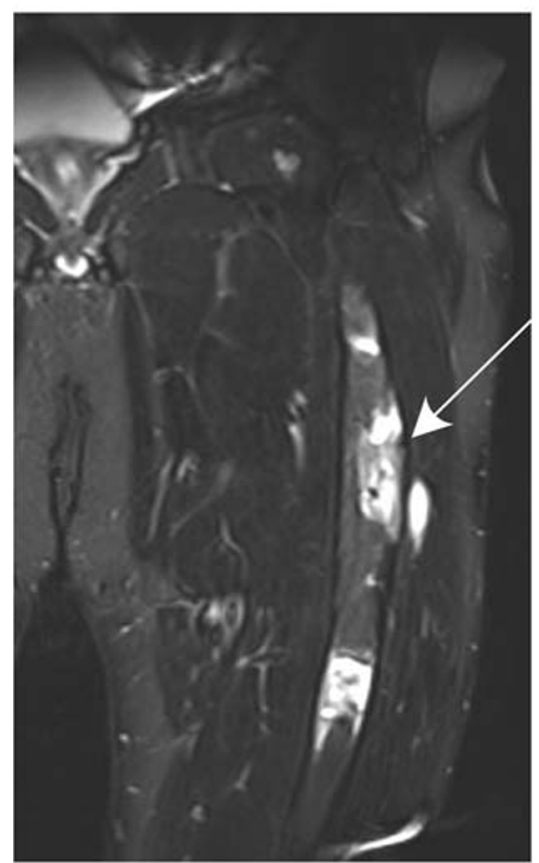

C

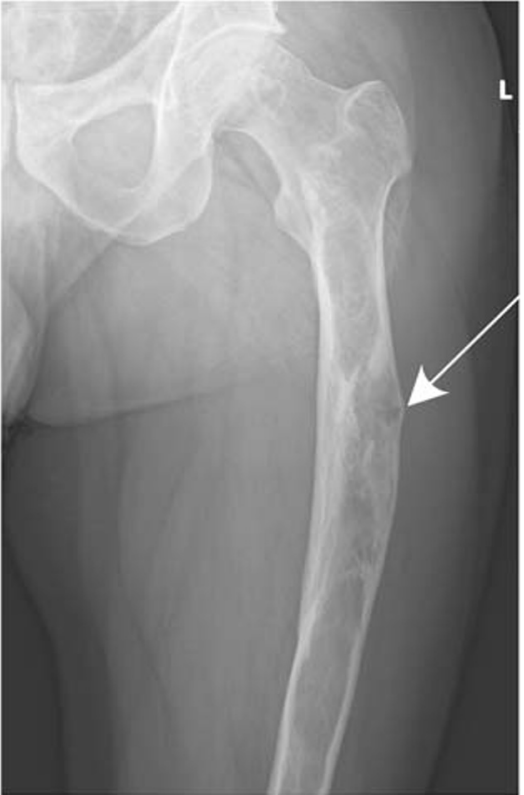

b

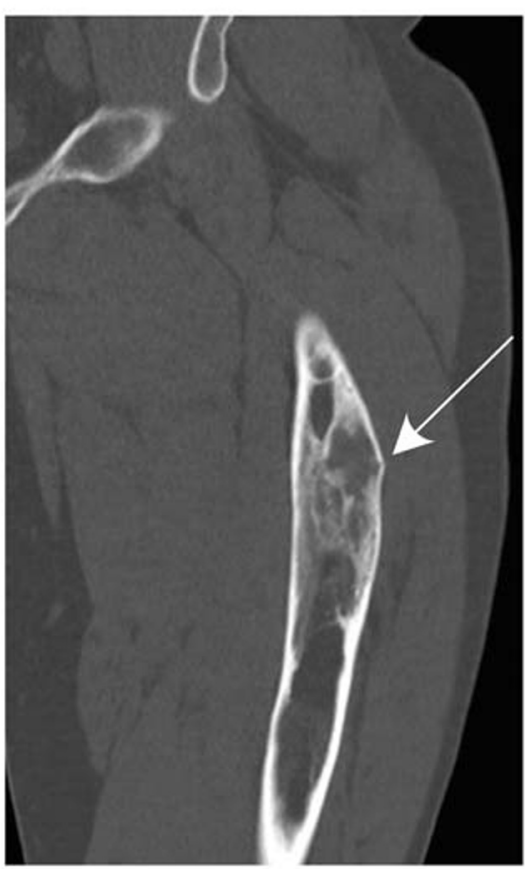

d

\section{Compliance with ethical standards}

Conflict of interest The authors declare that they have no conflict of interest.

Informed consent Informed consent was obtained from the patient for use of their images and clinical information.

\section{References}

1. Soubrier M, Dubost J-J, Boisgard S, Sauvezie B, Gaillard P, Michel $\mathrm{JL}$, et al. Insufficiency fracture. A survey of 60 cases and review of the literature. Jt Bone Spine. 2003;70:209-18.

2. Flanagan AM, Delaney D, Donnell PO, O'Donnell P. The benefits of molecular pathology in the diagnosis of musculoskeletal disease. Skelet Radiol. 2010;39:105-15. 
3. Calleja M, Amary F, O'Donnell P, Donnell PO. Mutational analysis of high-grade spindle cell sarcoma of the femur in Mazabraud's syndrome. Skeletal Radiology. 2019;48:151-7.

4. Lumbroso S, Paris F, Sultan C. Activating Gsalpha mutations: analysis of 113 patients with signs of McCune-Albright syndrome-a European collaborative study. J Clin Endocrinol Metab. 2004;89: 2107-13.

5. Henschen F. Fall von Ostitis fibrosa mit multiplen Tumoren in der umgebenden Muskulatur. Verh Dtsch Ges Pathol. 1926;21:93-7.

6. Mazabraud A, Semat P, Roze R. Apropos of the association of fibromyxomas of the soft tissues with fibrous dysplasia of the bones. Presse Med France. 1967;75:2223-8.
7. Nielsen GP, O'Connell JX, Rosenberg AE. Intramuscular myxoma: a clinicopathologic study of 51 cases with emphasis on hypercellular and hypervascular variants. Am J Surg Pathol. 1998;22:1222-7.

8. Multani I, Popovic S, Parasu N, Ghert M. Osteosarcomatous transformation in the setting of Mazabraud's syndrome: a case report and review of the literature. Ahlmann ER. Case Rep Orthop. Hindawi; 2019;2019:2638478.

9. Iwasko N, Steinbach LS, Disler D, Pathria M, Hottya GA, Kattapuram S, et al. Imaging findings in Mazabraud's syndrome: seven new cases. Skeletal Radiol Germany. 2002;31:81-7.

Publisher's note Springer Nature remains neutral with regard to jurisdictional claims in published maps and institutional affiliations. 